\title{
Severe Cardiac Dysfunction in Pregnancy- A Maternal Near Miss
}

\author{
Ruby Bhatia ${ }^{1}$, Sunita Mor², Sajaad Manzoor ${ }^{3}$, Vidya Khatri ${ }^{4}$
}

\begin{abstract}
${ }^{1}$ Department of Obstetrics and Gynaecology, Maharishi Markandeshwar Institute of Medical Sciences and Research, Mullana, Ambala, Haryana, India. ${ }^{2}$ Department of Obstetrics and Gynaecology, Maharishi Markandeshwar Institute of Medical Sciences and Research, Mullana, Ambala, Haryana, India. ${ }^{3}$ Department of Cardiology, Maharishi

Markandeshwar Institute of Medical Sciences and Research, Mullana, Ambala, Haryana, India. ${ }^{4}$ Department of Obstetrics and Gynaecology, Maharishi Markandeshwar Institute of Medical Sciences and Research, Mullana, Ambala, Haryana, India.
\end{abstract}

\section{INTRODUCTION}

Maternal near miss is defined as a pregnancy which survived a complication that occurred during pregnancy, childbirth or within 42 days of termination of pregnancy.[1] India's MMR has significantly declined from 167 in 2011-13 to 130 in 2014-16. According to guidelines on Maternal Near Miss given by Ministry of Health and Family Welfare, December 2014, for diagnosing a patient with severe cardiac dysfunction, grade-4 (WHO classification) which is a contra -indication to pregnancy, who met single heart criteria to be defined as MNM with abnormal acid-base values, need for ventilatory support, ICU admission, digitalisation, use of cardio- tonics, inotrope support, intra-cardiac intervention OR patient should meet minimum three criteria one each from clinical findings, investigations and interventions. There are certain single heart criteria like breathlessness, orthopnoea, tachycardia, organic murmurs, abnormal ECG and abnormal 2-D ECHO which puts the patient as MNM.[3]

Worldwide SAFE MOTHERHOOD remains the main aim of multi-speciality antenatal care in every maternal near miss and high-risk pregnancy. Primary aim is to prevent overall maternal mortality due to direct and indirect causes. Maternal near miss constitutes those pregnancies which survived a complication that occurred during pregnancy, childbirth or within 42 days of termination of pregnancy.[1]

Cardiac disease stage 4 (WHO) which is a contra-indication in pregnancy is an important indirect cause of maternal near miss as well as maternal mortality.[2] We report an undiagnosed case of severe cardiac dysfunction (WHO STAGE 4) with RHD with MR with severe pulmonary artery hypertension with severe anaemia with IUGR who reported as unbooked pregnancy in early third trimester for the first time in pregnancy as maternal near miss.[2] Indeed, severe cardiac dysfunction was diagnosed in $3^{\text {rd }}$ trimester at this visit only but with an excellent teamwork amongst obstetrician, cardiologist and ICU team achieved a safe motherhood with healthy baby. However, prolonged ventilatory and inotrope support with furosemide infusion needs to be highlighted with frequent and repeated transfer from high dependency obstetric unit to cardiac care unit till discharge after delivery. ${ }^{[4]}$

We report an unbooked case of severe cardiac disease (WHO stage 4) reported as maternal near miss for the first time in third trimester of pregnancy with cardiac dysfunction diagnosed during pregnancy in this visit. This case reported at 7 months gestation with rheumatic heart disease with severe MR, moderate AR in atrial fibrillation with congestive heart failure with severe pulmonary artery hypertension with EF 40\% with severity $82 \%$ (NYHA grade 4), a contra-indication to pregnancy as MNM.[1]-[2]

\author{
Corresponding Author: \\ Dr. Vidya Khatri, \\ C-101, Ganesh Nagar, \\ Tilak Nagar, \\ New Delhi-18, India. \\ E-mail: kkhatrivvidya24@gmail.com
}

DOI: $10.14260 /$ jemds/2020/152

Financial or Other Competing Interests: None.

How to Cite This Article:

Bhatia R, Mor S, Manzoor S, et al. Severe cardiac dysfunction in pregnancy- a maternal near miss. J. Evolution Med. Dent. Sci. 2020;9(09):700-702, DOI: 10.14260/jemds/2020/152

Submission 23-12-2019,

Peer Review 04-02-2020,

Acceptance 11-02-2020,

Published 02-03-2020.

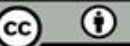




\section{PRESENTATION OF CASE}

An unbooked Primigravida, 24 yrs. old at 7 months amenorrhoea reported for the first time in emergency obstetric care unit with severe breathlessness, cold-clammy extremities, BP-90/60 mmHg, RR-38 per min, $\mathrm{SpO}_{2}$ at $80 \%$ on room air and raised JVP. Patient diagnosed as primigravida with 7-months gestation with foetal growth restriction with severe anaemia with RHD, severe pulmonary hypertension, severe MR, moderate AR in Atrial fibrillation with congestive heart failure admitted as maternal near miss. Patient was transferred to cardiac ICU. Immediate resuscitation was done by cardiology and medicine team. Haemoglobin was built up with 5 units PRBCs transfusion. Patient was shifted back to labour ward on treatment with tablet metoprolol $25 \mathrm{mg}$ OD, injection Lasix $20 \mathrm{mg}$ BD and injection benzathine penicillin $1.2 \mathrm{mIU}$ I/M every 3 weeks and other supportive treatment. Patient was frequently shifted to cardiology ICU in view of RHD with severe MR with grade -4 Pulmonary artery hypertension (WHO STAGE 4). Throughout her stay in HDU the patient was kept propped up, had persistent tachycardia and raised JVP with foetal growth restriction and severe anemia, $\mathrm{Hb}-5 \mathrm{gm} \%$. Ultrasound done confirmed single live intrauterine pregnancy with 33 weeks' gestation with foetoplacental insufficiency with IUGR. In view of foetal growth restriction, cervical ripening and Induction of labour was initiated after pre -induction assessment by ICU and cardiology team at 38 weeks. Prophylactic Epidural catheterization was initiated in active labour at $5 \mathrm{cms}$ dilatation for pain relief. In first stage of labour, patient again became MNM with $\mathrm{BP}-80 / 60 \mathrm{mmHg}$, RR of 38 per min, $\mathrm{SpO}_{2}$ $-88 \%$ on room air and was immediately shifted to Cardiac ICU. She was started with Lasix drip at $10 \mathrm{mg} / \mathrm{hr}$, nor-adrenaline at $0.1 \mathrm{mcg} / \mathrm{kg} / \mathrm{min}$ and then tapered down subsequently. A LSCS wide general anaesthesia done due to non- reassuring foetal heart rate. She delivered a live female baby weighing $2.097 \mathrm{Kgs}$ with Apgar score of 8 at 1 minute and 9 at 5 minutes. In postoperative period, patient developed acute cardiac failure, heart chambers got dilated and $\mathrm{EF}<35 \%$. She was kept on $\mathrm{AC} / \mathrm{VCV}$ mode of ventilator with Lasix at $20 \mathrm{mg} / \mathrm{hr}$, noradrenaline at $0.1 \mathrm{mcg} / \mathrm{kg} / \mathrm{min}$, amiodarone at $1 \mathrm{mg} / \mathrm{min}$, with adequate sedation and paralysis which was tapered down subsequently. Patient was securely managed with the team work of skilled obstetricians and cardiologists and was discharged in stable condition on post-operative day 21 .

\section{DISCUSSION}

Severe cardiac disease is a leading cause of maternal death in pregnancy in many developed countries, including the UK. Many of these women will never have undergone medical screening and some will be unaware that they have valvular heart disease. This highlights the need for a particularly careful cardiovascular assessment at the beginning of pregnancy of all women not born in a country where there is effective medical screening in childhood, including auscultation of the heart. [4] Women at significant risk of adverse events during pregnancy should be seen regularly in the antenatal clinic, whenever possible by the same consultant obstetrician, who should have appropriate competencies in this field. A further multidisciplinary meeting should take place at 32-34 weeks of gestation to establish a plan of management for delivery.

Cardiac disease in pregnant patient can present challenges in maternal - foetal management. It is important to note that in normal patients, pregnancy imposes some dramatic physiological changes upon cardiovascular system.[5] This unbooked case presented for the first time in obstetric emergency ward at 7 month amenorrhea with severe anaemia, tachycardia, with RHD with moderate MR, TR with EF 35\% with severe pulmonary artery hypertension in congestive heart failure with grade -4 cardiac disease (WHO), a contraindication in pregnancy as maternal miss. ${ }^{[6]}$

Women with heart disease are at a risk of cardiac complications during pregnancy and parturition. Risk assessment and pre- pregnancy counselling in severe cardiac disease should be done in these women and the management of pregnancy and delivery should be planned accordingly preferably during early first trimester. Depending upon the risk, women should be cared for in specialised centres. Multidisciplinary teams must be involved in the care of these women. [7] The physiological changes of pregnancy are often well tolerated by these women but may also induce complications such as heart failure, arrhythmias and thromboembolic events. ${ }^{[8]}$ These women should receive both cardiology and obstetric care throughout pregnancy and when delivery approaches the anaesthesia and neonatology team should also be involved. A plan should be formulated which include- timing of delivery, mode of delivery, regional anaesthesia, advice about medication during delivery and lactation and a plan for observation after delivery.

\section{CONCLUSIONS}

Cardiovascular disease affects approximately $1-4 \%$ of the nearly 4 million pregnancies in the US each year.[9] Such unbooked pregnancies with severe cardiac dysfunction became maternal near miss twice in antenatal period. Safe motherhood initiative with early assessment of high-risk pregnancy and aggressive intervention through the teamwork of skilled obstetrician and cardiology care as required helps reduce severe acute maternal morbidity (SAMM) as well as maternal death.[10],[11]

\section{REFERENCES}

[1] World Health Organization. Evaluating the quality of care for severe pregnancy complications: the WHO near-miss approach for maternal health. 2011.

[2] Thorne S, Nelson-Piercy C, MacGregor A, et al. Pregnancy and contraception in heart disease and pulmonary arterial hypertension. J Fam Plann Reprod Health Care 2006;32(2):75-81.

[3] Kalisa R, Rulisa S, Van den Akker T, et al. Maternal near miss and quality of care in a rural Rwandan hospital. BMC Pregnancy and Childbirth 2016;16(1):324. 
[4] Ray P, Murphy GJ, Shutt LE. Recognition and management of maternal cardiac disease in pregnancy. British Journal of Anaesthesia 2004;93(3):428-39.

[5] Elkayam U. Cardiac problems in pregnancy. John Wiley \& Sons Ltd., Sep 2, 2019.

[6] McFaul PB, Dornan JC, Lamki H, et al. Pregnancy complicated by maternal heart disease. A review of 519 women. BJOG: An International Journal of Obstetrics \& Gynaecology 1988;95(9):861-7.

[7] Curtis SL, Marsden-Williams J, Sullivan C, et al. Current trends in the management of heart disease in pregnancy. International Journal of Cardiology 2009;133(1):62-9.
[8] Regitz-Zagrosek V, Roos-Hesselink JW, Bauersachs J, et al. 2018 ESC Guidelines for the management of cardiovascular diseases during pregnancy. European Heart Journal 2018;39(34):3165-241.

[9] Elkayam U, Goland S, Pieper PG, et al. High-risk cardiac disease in pregnancy: part I. Journal of the American College of Cardiology 2016;68(4):396-410.

[10] Say L, Pattinson RC, Gülmezoglu AM. WHO systematic review of maternal morbidity and mortality: the prevalence of severe acute maternal morbidity (near miss). Reproductive Health 2004;1(1):3.

[11] Mahler H. The safe motherhood initiative: a call to action. Lancet (London, England) 1987;1(8534):668-70. 